\title{
Screening of Mandarin Oil on Indomethcin Induced Inflammatory Bowel Disease in Wistar Rats
}

\author{
Nitin R Patil, Vijaykumar P Rasal, Rohit Hanumantrao Malabade* \\ Department of Pharmacology, KLEU's College of Pharmacy, Belgaum, INDIA
}

\begin{abstract}
Objective: The present study investigates the protective effect of Mandarin Oil against Indomethacin (INDO) induced Inflammatory Bowel Disease (IBD) in male Wistar rats. Material and Method: IBD was induced by administration of indomethacin solution $(7.5 \mathrm{mg} / \mathrm{kg}$ b.w., s.c) for 2 days. The study compromises of $5 \mathrm{groups}$ $(n=6)$, normal saline treated, disease induced, Mandarin Oil-I $(200 \mathrm{mg} / \mathrm{kg})$, Mandarin Oil-II $(400 \mathrm{mg} / \mathrm{kg})$ and Sulfasalazine (standard drug, $500 \mathrm{mg} / \mathrm{kg} \mathrm{b.w,} \mathrm{p.o)} \mathrm{treated} \mathrm{group.} \mathrm{After} \mathrm{treatment} \mathrm{period} \mathrm{animals} \mathrm{were} \mathrm{sacrificed}$ by cervical dislocation and dissected. Ileum was isolated for macroscopic, microscopic and biochemical studies. Results: Pre-treatment with Mandarin oil shows decrease in macroscopic score for inflammation as compared to indomethacin treated group. Histopathological examination of Mandarin oil treated group revealed less damage compared to indomethacin treated group. Conclusion: Mandarin oil have shown to be effective in indomethacininduced enterocolitis in rats, which has protected the animals against experimentally induced disease because of its antioxidant and anti-inflammatory activities.
\end{abstract}

Key words: mandarin oil, inflammatory bowel disease, indomethacin, sulfasalazine and anti-oxidant.

\section{INTRODUCTION}

Crohn's disease and ulcerative colitis are two idiopathic inflammatory bowel disorders. Inflammatory bowel disease is now thought to represent an inappropriate response of the intestinal mucosal immune system which leads to upregulation of the synthesis and release of different pro inflammatory mediators, including eicosanoids, platelet activating factor, cytokines and reactive oxygen and nitrogen metabolites. ${ }^{1}$ The infiltrated and activated neutrophils represent an important source of reactive oxygen and nitrogen species. Free radicals, neutrophils can also release proteases, lactoferrin and lipid mediators that can contribute to intestinal injury. Macrophages produce certain cytokines, such as tumor necrosis factor $(\mathrm{TNF}-\alpha)$ and interleukin, the levels of which are often increased in both animal models and patients with ulcerative colitis. ${ }^{2}$ In many studies, it has been reported that antioxidants show beneficial effects on experimental colitis. ${ }^{3}$ It has been suggested that the imbalance between pro-oxidant and antioxidant mechanisms in IBD may be controlled by antioxidant treatment. ${ }^{4}$ Mandarin oil possess antioxidant property and this situation, requires an external supply of antioxidants which is necessary to regain a balance between free radicals and antioxidants. ${ }^{5}$ Traditionally oil is used as antidyspeptic, antiscorbutic, stomachic, astringent, carminative, tonic, antiulcer, colic, anthelmintic, antidiarrhoeal, appetizer, and in spasmodic affection, helminthiaisis, bilious diarrhoea $\&$ dyspepsia. ${ }^{6}$ The chemical constituents viz. limonoids, flavonoids (flavonone glycoside), phenolic acid are present in the Mandarin oil. The peel of citrus fruits is a rich source of flavonone and many polymethoxylated flavones, which are very rare in other plants. ${ }^{7}$

Previously Mandarin oil has shown antioxidant, antifungal, antimicrobial, diabetic,
Submission Date : 10-04-13

Revision Date : :22-09-14 Accepted Date : :06-11-14

DOI: $10.5530 /$ ijper.48.4s.1 Correspondence Address Mr. Rohit. H. Malabade KLEU's College of Pharmacy, Belgaum, Karnataka 590010.Email: malabade_rohit@yahoo.co.in

Mobile: 8050595974

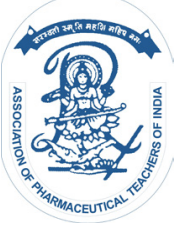

www.ijper.org 
hepatoprotective, antianxiety and anticancer properties. $^{8-13}$

The present study is to investigate the effects of Mandarin oil on the experimental model of colitis induced by trinitrobenzenesulphonic acid (TNBS) in wistar rats, it is well established model of inflammatory bowel disease that has same histological and biochemical features of human disease.

\section{MATERIALS AND METHODS}

\section{Animals}

Healthy male Wistar rats weighing 200-250 g were used in the study. Animals were harbored on a 12-h light/dark cycle at a constant ambient temperature (24 $\pm 1^{\circ} \mathrm{C}$ ) with normal rat chow and water available ad libitum. The study was reviewed and approved by the Institutional Animal Ethical Committee.

\section{Acute Oral Toxicity Study}

The acute oral toxicity was carried out as per Guidelines set by OECD, revised draft guidelines 423. The Mandarin oil sample did not exhibit any toxicity symptoms and mortality when given orally at dose of 2000 $\mathrm{mg} / \mathrm{kg}$ body weight. Hence $1 / 10^{\text {th }}$ and $1 / 5^{\text {th }}$ i.e. 200 $\mathrm{mg} / \mathrm{kg}$ and $400 \mathrm{mg} / \mathrm{kg}$ b.w. were selected for the study.

\section{Indomethacin (INDO) Induced Enterocolitis in rats $^{14}$}

30 animals were randomly divided into five groups, each consisting of 6 animals as follows. Group 1 served as a normal control and maintain on regular rat food and drinking water ad libitum. All remaining Groups received $7.5 \mathrm{mg} / \mathrm{kg}$ indomethacin (solubilized in $100 \%$ alcohol then diluted with $5 \% \mathrm{w} / \mathrm{v}$ sodium bicarbonate solution). Group 2 animals received indomethacin without any treatment. Group 3 and 4 are pre-treated with Mandarin oil in dose of $200 \& 400 \mathrm{mg} / \mathrm{kg}$, prior to administration of indomethacin on $08^{\text {th }}$ and $09^{\text {th }}$ day. Mandarin oil was continued till $11^{\text {th }}$ day. Group 5 served as standard drug treated group, which received indomethacin and treated with sulfasalazine which was suspended in distilled water using $0.5 \% \mathrm{w} / \mathrm{v} \mathrm{CMC}$ solution and administered orally.

\section{Assessment parameters}

\section{Feed Intake}

Weighed amount of feed was given to the rat every day. The feed intake was calculated by subtracting the remaining feed with the given feed weight.

\section{Macroscopic Scoring ${ }^{15}$}

Blood was collected through retro-orbital puncture. Following the blood collection, the animals were sacrificed and the small intestine (ileum segment) were excised and opened longitudinally. Gross findings were ranked using the following criteria, 0 - No change in both serosa and mucosa, 1-hyperemia and petechial, bleeding, 2-single mucosal erosion or ulceration, 3 -single mucosal erosion or ulcer with hyperemic, adhesive or hemorrhagic lesions in the serosa and mesentery, 4-multiple erosions or ulcerations (less than $10 \mathrm{~cm}$ ), 5-Multiple erosions or ulcerations (more than $10 \mathrm{~cm}$ )

\section{Biochemical Assays}

\section{Serum Lactate Dehydrogenase (LDH) ${ }^{16}$}

The serum was used for determination of $\mathrm{LDH}$, indicator of tissue damage by using commercially available diagnostic kit (ERBA Diagnostics, Mannhim GmbH, Germany).

\section{Myeloperoxidase (MPO) Assay ${ }^{17}$}

Pieces of inflamed tissues (rat colon $-2 \mathrm{~cm} / \mathrm{rat}$ ileum $-2 \mathrm{~cm}$ ) were taken. The tissue was then rinsed with ice-cold saline, blotted dry, weighed and excised. Minced tissue was homogenized in 10 volumes of icecold potassium phosphate buffer $(\mathrm{pH}$ 7.4) using tissue homogenizer. The homogenate was centrifuged at 3500 rpm for $30 \mathrm{~min}$ at $4^{\circ} \mathrm{C}$. The supernatant was discarded, $10 \mathrm{ml}$ of ice-cold $50 \mathrm{mM}$ potassium phosphate buffer ( $\mathrm{pH}$ 6.0) containing $0.5 \%$ hexadecyltrimethyl ammonium bromide (HETAB) and $10 \mathrm{mM}$ EDTA was then added to the pellet. It was then subjected to one cycle of freezing and thawing for brief period $(15 \mathrm{sec})$ of sonication. After sonication solution was centrifuged at 15,000 rpm for 20 min. Myeloperoxidase (MPO) activity was measured spectrophotometrically as follows: $0.1 \mathrm{ml}$ of supernatant was combined with $2.9 \mathrm{ml}$ of $50 \mathrm{mM}$ phosphate buffer containing $0.167 \mathrm{mg} / \mathrm{ml}$ O-dianisidine hydrochloride and $0.0005 \% \mathrm{H}_{2} \mathrm{O}_{2}$. The change in absorbance was measured spectrophotometrically, at $460 \mathrm{~nm}$.

\section{Calculation of MPO activity}

MPO activity $=\frac{X}{\text { wt of the peice of the tissue taken }}$

Where; $X=\frac{10 \times \text { Change in Absorbance per Minute }}{\text { Vol of Supernatent taken in final rean }}$

\section{Colonic glutathione content: (GSH) ${ }^{16}$}

Briefly, GSH in tissue homogenate was reacted with Ellman's reagent (5, 5-dithio-2-nitrobenzoic acid) in phosphate buffer saline (PBS, $\mathrm{pH}$ 8.0) and the absorbance was measured at $412 \mathrm{~nm}$. 


\section{Assay Procedure}

\begin{tabular}{|l|c|c|}
\multicolumn{1}{|c|}{ Reagents } & Blank & Test \\
\hline Ellman's reagent & $50 \mu \mathrm{l}$ & $50 \mu \mathrm{l}$ \\
\hline Reaction buffer & $2.5 \mathrm{ml}$ & $2.5 \mathrm{ml}$ \\
\hline $\begin{array}{l}\text { Tissue } \\
\text { homogenate }\end{array}$ & - & $250 \mu \mathrm{l}$ \\
\hline
\end{tabular}

Mix well and incubated at room temperature for 15 minuteAbsorbance measured at $412 \mathrm{~nm}$ on UV spectrophotometer.

\section{Calculation}

GSH Mole $=\frac{\text { Absorbance }}{1.4550 \times 10^{4}} \times 11.2$ Mole

\section{Colonic lipid peroxides concentration (LPO) ${ }^{16}$}

Lipid peroxidation, an indicator of mucosal injury induced by reactive oxygen species was measured as thiobarbituric acid reactive substance. Briefly, $0.5 \mathrm{ml}$ of colonic tissue homogenates prepared were reacted with $2 \mathrm{ml}$ of TBA reagent containing $0.375 \%$ TBA, $15 \%$ trichloroacetic acid and $0.25 \mathrm{~N} \mathrm{HCl}$. Samples were boiled for $15 \mathrm{~min}$, cooled and centrifuged. Absorbance of the supernatants was measured by spectrophotometer measured at $532 \mathrm{~nm}$.

\section{Calculation}

Concentration $(\mu M)=\frac{\text { Absorbance }}{\text { Molar extinction coefficient }} \times 10^{6}$

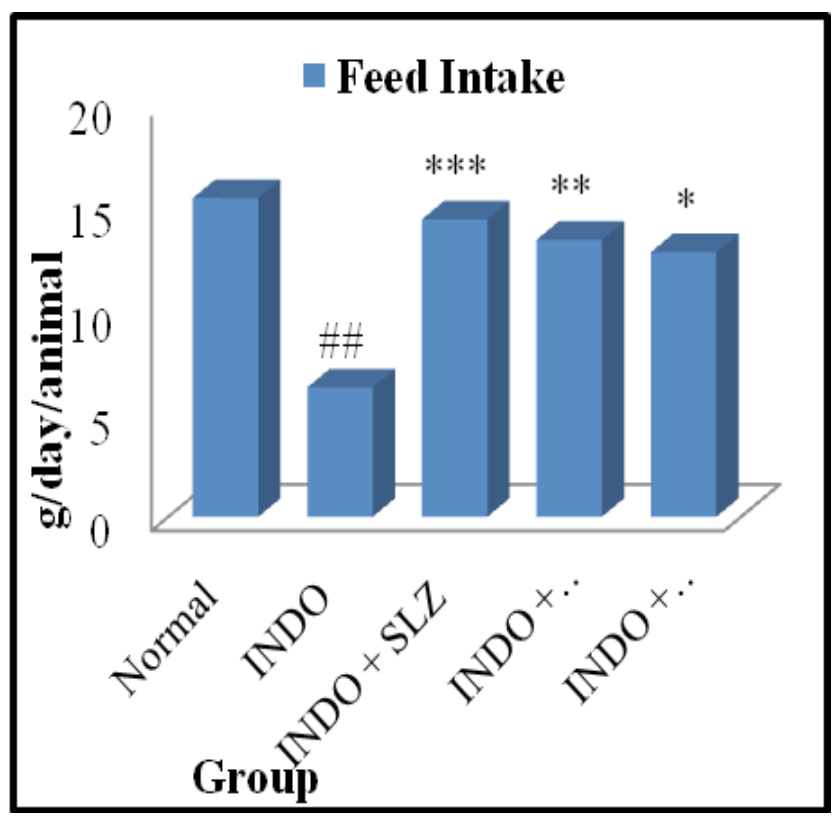

Figure 1: Effect of MO on Feed intake
Final Concentration of unknown sample/gram tissue $=$ $100 \times \mu$ M LPO equivalent/gram tissue.

\section{Histopathological Studies ${ }^{18}$}

A portion of inflamed ileum was fixed in phosphatebuffered formaldehyde and embedded in paraffin and $5 \mu \mathrm{m}$ sections were prepared. Tissues were stained with hematoxylin and eosin and were evaluated by light microscopy.

\section{Statistical Analysis}

Results were expressed as Mean \pm SEM. The statistical significance of any difference in each parameter among the groups was evaluated by one-way ANOVA, using Dunnet's t test as post hoc test.

\section{RESULTS}

\section{Indomethacin Induced Enterocolitis in Rats}

\section{Feed Intake and Macroscopic Score}

There was severe anorexia in indomethacin treated group with decrease in average feed intake $(\mathrm{P}<0.01)$ as shown in (Figure: 1). Macroscopic evidence of extensive colonic mucosal injury was assessed by the macroscopic score (Figure: 2). MO-I treated group showed a significant $(\mathrm{P}<0.001)$ decrease in macroscopic score, whereas less significant $(\mathrm{P}<0.05)$ decrease was observed with MO-II treatment as compared to that of indomethacin treated group.

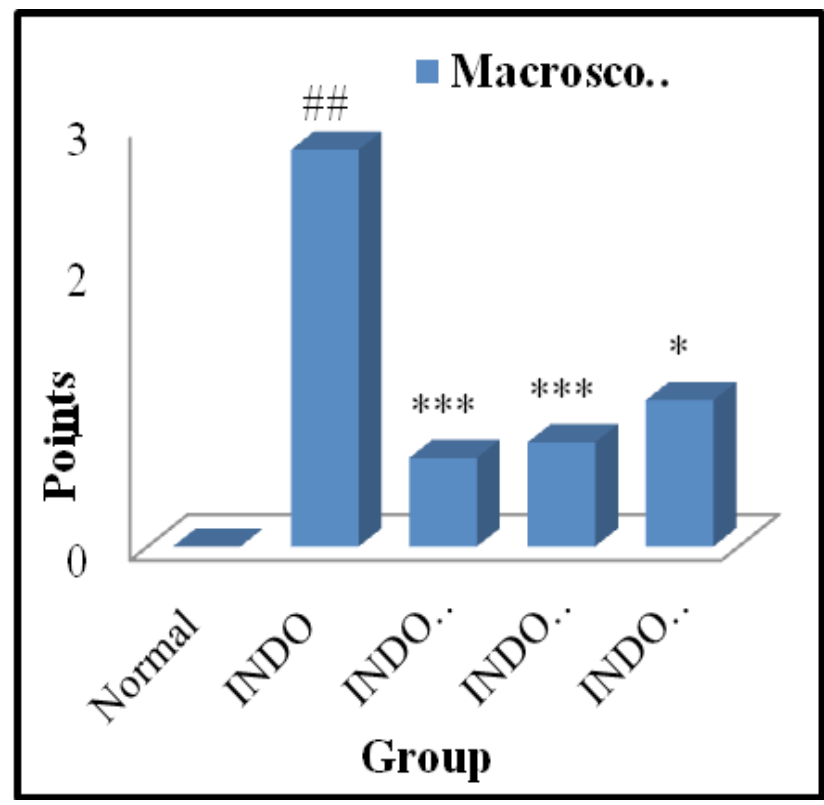

Figure 2: Effect of MO on Macroscopic score in Indomethacin induced enterocolitis in rats. 


\begin{tabular}{|c|c|c|c|c|c|c|}
\hline Group & $\begin{array}{c}\text { MPO activity } \\
\text { (units/g) }\end{array}$ & $\begin{array}{l}\text { Serum LDH } \\
\text { (units/litre) }\end{array}$ & $\begin{array}{c}\text { Colonic GSH } \\
\text { concentration } \\
\text { (nmol/g of wet } \\
\text { tissue) }\end{array}$ & $\begin{array}{c}\text { Colonic LPO } \\
\text { concentration } \\
\text { ( } \mu \mathrm{g} / \mathrm{g} \text { of wet } \\
\text { tissue) }\end{array}$ & $\begin{array}{c}\text { Feed intake (g/ } \\
\text { day/animals) }\end{array}$ & $\begin{array}{l}\text { Macroscopic } \\
\text { score (points) }\end{array}$ \\
\hline Normal & $0.1805 \pm 0.001$ & $1688 \pm 13.713$ & $1226 \pm 3.138$ & $45.41 \pm 1.11$ & $15.41 \pm 0.184$ & 0.0 \\
\hline INDO Treatment & $0.4278 \pm 0.002^{\# \#}$ & $3525 \pm 16.967$ & $929 \pm 2.186^{\# \#}$ & $83.23 \pm 0.89^{\# \#}$ & $6.26 \pm 0.1206^{\# \#}$ & $2.82 \pm 0.02^{\# \#}$ \\
\hline INDO+ SLZ & $0.2048 \pm 0.001^{* * *}$ & $1751 \pm 11.406^{* * *}$ & $1189 \pm 1.701^{* * *}$ & $52.67 \pm 1.30 * * *$ & $14.38 \pm 0.07^{* * *}$ & $0.63 \pm 0.01^{* * *}$ \\
\hline INDO + MO-I & $0.4092 \pm 0.006^{* *}$ & $2219 \pm 23.56^{* * *}$ & $1101 \pm 7.346^{* * *}$ & $61.32 \pm 0.45^{* * *}$ & $13.39 \pm 0.10^{* *}$ & $0.74 \pm 0.01^{* * *}$ \\
\hline INDO + MO-II & $0.2372 \pm 0.001^{*}$ & $1861 \pm 13.37^{*}$ & $1015 \pm 1.317^{*}$ & $66.99 \pm 0.48^{*}$ & $12.80 \pm 0.05^{*}$ & $1.04 \pm 0.21^{*}$ \\
\hline \multicolumn{7}{|c|}{ 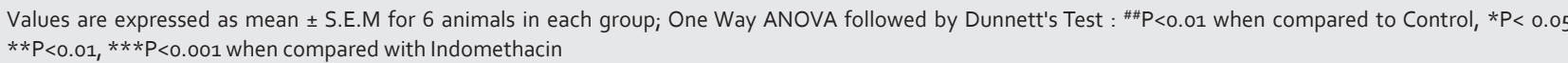 } \\
\hline
\end{tabular}
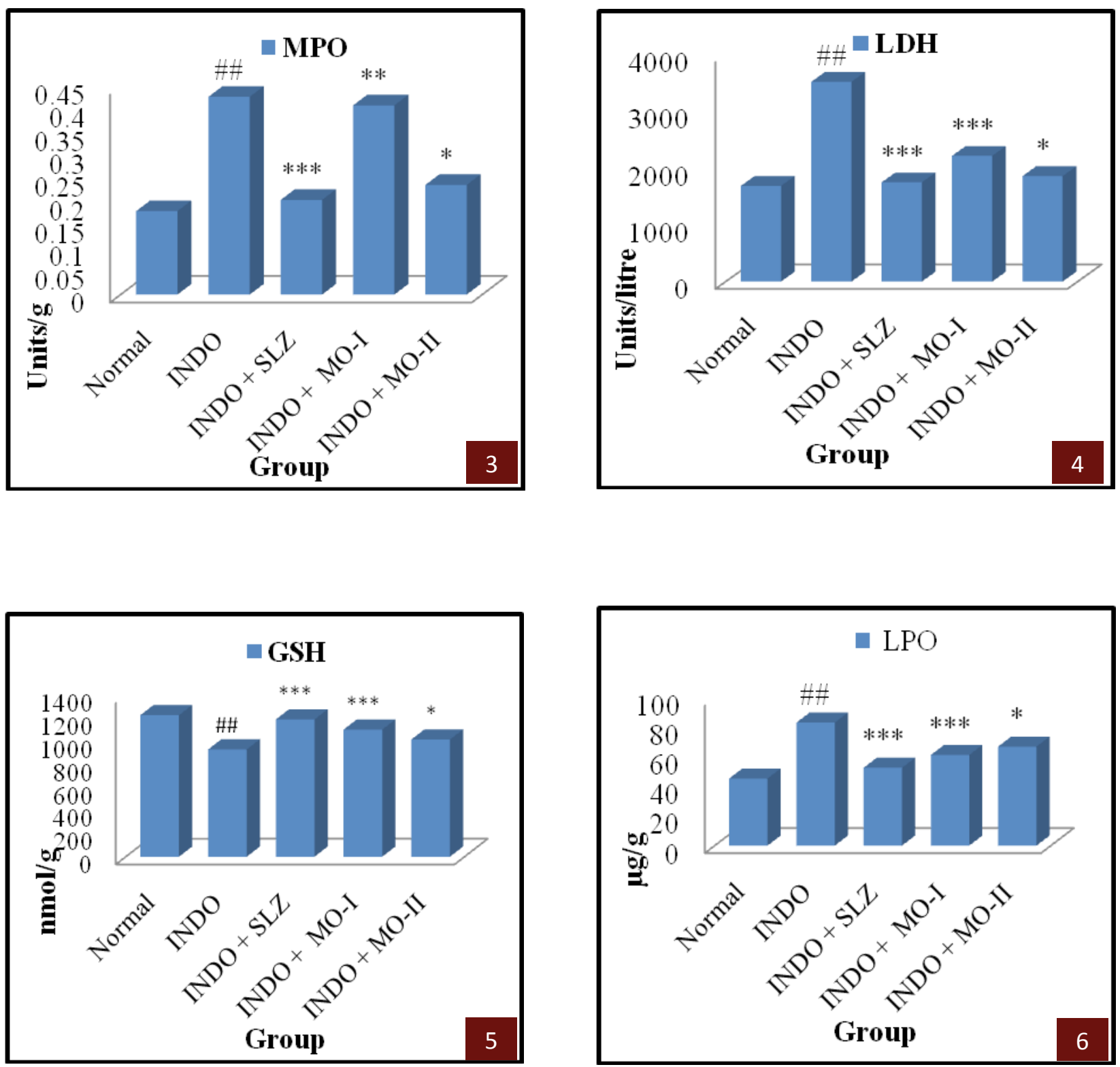

Effect of MO-on bio-chemical enzyme, MPO (Figure 3), LDH (Figure 4), GSH (Figure 5) and LPO (Figure 6) in Indomethacin induced enterocolitis in rats.

Values are expressed as mean \pm SEM for 6 animals in each group, One Way ANOVA followed by Dunnett's Test, \#\#P<0.01 when compared to Control, *P<0.05, **P<0.01, $* * * P<0.001$ when compared with Indomethacin. 

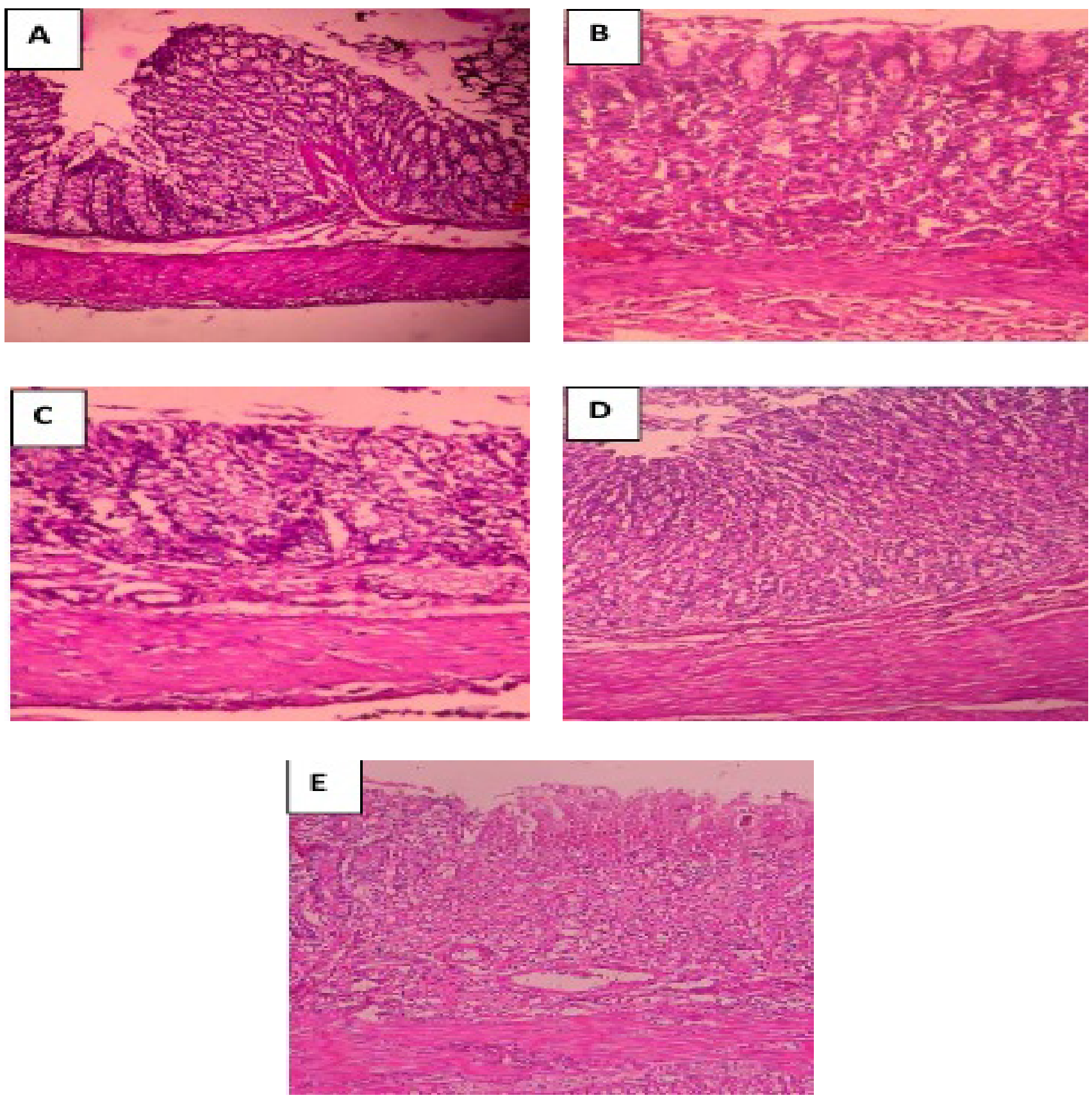

Figure No: 7 (A_E) Histopathological images of normal and treated ileum

\section{Biochemical Assays}

Effect of Mandarin Oil treatment $(200 \mathrm{mg} / \mathrm{kg}$ and 400 $\mathrm{mg} / \mathrm{kg}$ ) on Myeloperoxidase (MPO), Colonic glutathione (GSH), Colonic Lipid Peroxides (LPO) and Serum lactate dehydrogenase $(\mathrm{LDH})$ concentration is shown in Table.1 Biochemical assay shows that administration of INDO leads to extensive colonic mucosal injury with increase in macroscopic score, serum LDH level and MPO activity, colonic LPO and decrease in feed intake and colonic GSH content along with intestinal dysmotility and damage to colonic structure. Pre-treatment with $\mathrm{MO}$ was effective in reversing these parameters. MO- I was found to be more effective than MO II. His- tologically, damage was restored. The beneficial effects of MO are comparable to the standard drug SLZ (Figure 3-6).

\section{Histopathology}

The Histopathological changes of the normal and treated rat ileum are shown below. Fig. 7A - Normal ileum of rat showed intact mucosa and epithelial surface; 7B - INDO treated inflamed ileum of rat showing submucosa with severe infiltration and edema; 7C, 7D Ileum of MO treated (200 and $400 \mathrm{mg} / \mathrm{kg}$ respectively) rat showing recovered submucosal edema \& few inflammatory cells associated with Indomethacin adminstra- 
tion; 7E - Sulfasalazine treated rat showing recovered sub mucosal edema \& severity of cell damage.

\section{DISCUSSION}

The present study confirmed that treatment with the Mandarin oil, reduced the enterocolitis induced by TNBS and ethanol, as verified by macroscopic, histological and biochemical data.

Inflammatory bowel disease is characterized by the involvement of ROS in tissue damage. Increased granulocyte accumulation in inflammatory lesions of gut mucosa in patients with IBD has been shown. Those activated cells release a number of inflammatory mediators such as toxic oxygen metabolites, lysosome enzymes, and derivatives of arachidonic acid metabolism. It has been proposed that inflammation of mucosa causes impairment of the antioxidant defence mechanism, and makes tissue more susceptible to oxidative damage. ${ }^{19}$

In the present study, Mandarin oil has shown to be effective in indomethacin-induced enterocolitis in rats, which has protected the animals against experimentally induced disease because of its antioxidant and antiinflammatory activities. ${ }^{6,12}$ The Mandarin oil possess good antibacterial properties; therefore, it may be useful in combating intestinal or other pathogens, which play important role in the pathogenesis of IBD. It has antiulcer and antifungal actions, which might be useful in gastrointestinal disturbances \& disturbed GI motility occurring in inflammatory bowel conditions. The mechanism of development of disease in Indomethacin-induced enterocolitis involves role of protective prostaglandins and intestinal pathogens.

\section{CONCLUSION}

In conclusion, Mandarin oil may prove useful in the treatment of IBD. However, more detailed phytochemical studies are necessary to identify the active principles and exact mechanisms of action.

\section{ACKNOWLEDGEMENT}

Authors are thankful to Prof (Dr.) A. D. Taranalli and KLE college of Pharmacy, Belgaum for their support and encouragement.

\section{REFERENCES}

1. Julio Galvez A, Juliano de Souza Gracioso B, Desirée Camuesco, Julio Galvez, Wagner Vilegas, Alba Regina Monteiro Souza Brito, Antonio Zarzuelo. Intestinal antiinflammatory activity of a lyophilized infusion of Turnera ulmifoliain TNBS rat colitis. Fitoterapia. 2006; 77(7): 515-520.
2. Isabel Villegas, Carmen La Casa, Aurelio Orjales, Catalina Alarco ' $n$ de la Lastra. Effects of dosmalfate, a new cytoprotective agent, on acute and chronic trinitrobenzene sulphonic acid-induced colitis in rats. European Journal of Pharmacology. 2003; 460(2): 209-18.

3. Weder JE, Dillon CT, Hambley TW, Kennedy BJ, Lay PA, Biffin JR, Regtop $\mathrm{HL}$, Davies NM. Copper complexes of non-steroidal anti-inflammatory drugs: an opportunity yet to be realized. Coord Chem Rev. 2002; 232(1): 95-126.

4. Cetinkaya A, Bulbuloglu E, Kurutas EB, Ciralik H, Kantarceken B, Buyukbese MA. Benificial effect of $\mathrm{N}$ - acetylcystein on acetic acid induced colitis in rats. Tohoku J Exp Med. 2005; 206(2): 131-9.

5. Bamias G, Nyce MR, Delarue SA, Cominelli F. New concepts in the pathophysiology of inflammatory bowel disease. Ann Intern Med. 2005; 143(12): 895-904.

6. Chatterjee A, Pakrashi SC. The Treatise on Indian Medicinal Plants; Vol 2. Deep Publication; 1992. 92-4.

7. Tumbas VT, Cetkovic GS, Djilas SM, Brunet JMC, Vulic JJ, Knez Z, Skerget M. Antioxidant activity of Mandarin (Citrus reticulata) peel. APTEFF. 2010; 41: 195-203.

8. Chutia M, Bhuyan PD, Pathak MG, Sarma TG, Boruah P. Antifungal activity and chemical composition of Citrus reticulata blanco essential oil against phytopathogens from north east India. LebensonWiss Technol. 2009; 42(3): 777-80.

9. Gavimath CC, Kangralkar VA, Jadhav NA, Burli SC. Effect of essential oil of Citrus reticulata on blood glucose and lipid profile in alloxan induced diabetic rats. Int J Pharmaceut Appl. 2010; 1(1): 1-5.

10. Kangralkar VA, Gavimath CC, Vijapur V, Gowri B, Hooli VR, Mathapati P. Protective effect of essential oil of Citrus reticulataon isoniazid induced hepatotoxicity in wistar rats. Int J Pharmaceut Appl. 2010; 1(2): 59-61.

11. Gargano AC, Costa CARA, Costa M. Essential oils from Citrus latifolia and Citrus reticulata reduce anxiety and prolong ether sleeping time in mice. TFSB. 2008; 2(1): 121-4.

12. Mervat MA, Gendy EA. In vitro, evaluation of medicinal activity of egyptian honey from different floral sources as anticancer and antimycotic infective agents. JMBT. 2010; 2(5): 118-23.

13. Tumbas VT, Cetkovic GS, Djilas SM, Brunet JMC, Vulic JJ, Knez Z, Skerget M. Antioxidant activity of Mandarin (Citrus reticulata) peel. APTEFF. 2010; 41: 195-203.

14. Deshmukh CD, Pawar AT, Bantal V. Effect of Emblica officinalis methenolic fruit extract on indomethacin induced enterocolitis in rats. Res J Med Plant. 2010; 4(3): 141-8.

15. Yamada T, Deitch E, Specian RD, Perry MA, Sartor RB, Grisham MB. Mechanism of acute and chronic intestinal inflammation induced by indomethacin. Inflam. 1993; 17(6): 641-62.

16. Hagar $\mathrm{HH}$, Medany AE, Eta EE, Arafa M. Ameliorative effect of pyrrolidinedithiocarbamate on acetic acid induced colitis in rats. Eur $\mathrm{J}$ Pharmacol. 2007; 554(1): 69-77.

17. Al-Jarallah A, Oriowo MA, Khan I. Mechanism of reduced colonic contractility in experimental colitis: role of sarcoplasmic reticulum pump isoform-2. Mol Cell Biochem. 2007; 298(1-2): 169-78.

18. Jagtap AG, Shrike SS, Phadke AS. Effect of polyherbal formulation on experimental models of inflammatory bowel diseases. J Ethnopharmacol. 2004; 90(2): 195-204.

19. Murat MM, Ulvi D, Neslihan $Y$, Nese $K$, Ismail $T$, Serpil $F$, Cengiz ARA, Murat ALADA, Melih K, Fatih $\mathrm{H}$. The effect of Gingko biloba extract on acetic acid induced colitis in rats. Turk J Gastroenterol. 2006; 17(3): 177-82. 